Research Paper

\title{
Optimal Dose of Prophylactic Dexmedetomidine for Preventing Postoperative Shivering
}

\author{
Yong-Shin Kim ${ }^{1}$, Yong-Il Kim², Kwon-Hui Seo ${ }^{1 凶}$, Hye-Rim Kang1 \\ 1. Department of anesthesiology and pain medicine, Catholic University of Korea. \\ 2. Department of surgery, Ewha Womans University of Korea.
}

$\triangle$ Corresponding author: Dr. Kwon-Hui Seo at the Department of Anesthesiology and Pain Medicine, St. Vincent Hospital, Catholic University of Korea. Ji-dong, Paldal-gu, Suwon. Tel.: 8131249 7273, Fax: 8131258 4212, E-mail address: aneskim@catholic.ac.kr.

() Ivyspring International Publisher. This is an open-access article distributed under the terms of the Creative Commons License (http://creativecommons.org/ licenses/by-nc-nd/3.0/). Reproduction is permitted for personal, noncommercial use, provided that the article is in whole, unmodified, and properly cited.

Received: 2013.04.22; Accepted: 2013.07.29; Published: 2013.08.13

\begin{abstract}
Objective The aim of this study was to investigate the optimum dosage of dexmedetomidine for prevention of postanesthetic shivering.

Methods One-hundred thirty two ASA physical status I-II patients scheduled for elective laparoscopic total hysterectomy were enrolled in this randomised, placebo-controlled study. Patients were randomly allocated to receive dexmedetomidine in four groups: group $\mathrm{S}(0.9 \%$ normal saline), group D0.5 (dexmedetomidine $0.5 \mu \mathrm{g} / \mathrm{kg}$ ), group D0.75 (dexmedetomidine $0.75 \mu \mathrm{g} / \mathrm{kg}$ ), group DI.0 (dexmedetomidine $1.0 \mu \mathrm{g} / \mathrm{kg}$ ). Time to extubation and tympanic temperature during and after operation were measured. Shivering was graded ( $0-3$ scale) upon patients arrival to the PACU and every ten minutes thereafter up to forty minutes. Sedation and first rescue analgesic time at the PACU were evaluated.

Results The incidence of shivering was significantly lower in group D0.75 and DI.0 than in group $S(P<0.05)$. There were significantly fewer patients with a shivering score of 2 or 3 in groups $D 0.75$ and DI .0 than in group $S(P<0.05, P<0.00 I)$. Extubation time was shorter in group $S$ than in groups D0.75 and DI.0 $(P<0.05)$. Tympanic temperature at 40 minutes postoperatively in the recovery room was higher in group $S$ than in the other dexmedetomidine groups $(P<0.05)$

Fewer patients required rescue analgesia in groups D0.75 and DI.0 than in group $S(P<0.00 I)$, and the time to rescue analgesia was longer in group DI.0 than in group $S(P<0.00 I)$. Modified Observer's Assessment of Alertness/Sedation (MOAA/S) at arrival in the PACU was lower in all dexmedetomidine groups than in group $S(P<0.05)$.

Conclusions Our results suggest that dexmedetomidine 0.75 or $1.0 \mu \mathrm{g} / \mathrm{kg}$ provides effective prophylaxis against postoperative shivering as well as an analgesic effect. Though potential for intraoperative requirement for atropine, sedation in the immediate recovery period and delayed extubation time with dexmedetomidine was noted, there were no major clinical impacts on the overall recovery from anesthesia.
\end{abstract}

Key words: dexmedetomidine, sedation, postanesthetic shivering.

\section{Introduction}

Postanesthetic shivering is a common complication that occurs in 5-65\% of patients recovering from general anesthesia. ${ }^{1-2}$ It is distressing and unpleasant experience for patients. Excessive shivering can result in an increased oxygen demand up to $400 \%$ of normal and induce metabolic derangements such as hypoxemia, lactic acidosis and hypercarbia. ${ }^{1,3}$ Therefore, shivering may cause problems in patients with low cardiac and pulmonary reserves. ${ }^{4}$

Considering these undesirable consequences of 
shivering, measures to prevent in the postoperative period are important. Various drugs have been investigated for the prevention or treatment of postoperative shivering, including meperidine, ketamine, tramadol, doxapram and dexmedeomidine. ${ }^{5-8}$

Dexmedetomidine is an $\alpha$ 2-agonist that decreases vasoconstriction and shivering thresholds and when administered with meperidine additively reduces the shivering threshold in healthy volunteers. ${ }^{9}$ Intraoperative dexmedetomidine reduces postanesthetic shivering as does meperidine after surgery. ${ }^{10}$ One bolus dose of dexmedetomidine $1 \mu \mathrm{g} / \mathrm{kg}$ with or without continuous infusion was used in the previous antishivering studies. ${ }^{8,10}$ Dexmedetomidine also has sedative and analgesic effects in the postoperative period. ${ }^{8}$ Patients who received an intraoperative injection of dexmedetomidine were more sedated after surgery than those who received placebo. ${ }^{8}$ This can be a disadvantage particularly for patients undergoing outpatient surgery.

There has been no study regarding the optimal effective dose of dexmedetomidine for preventing postoperative shivering. Thus, the present study was conducted with the aims of identifying the dose of dexmedetomidine that provides antishivering as well as analgesic effects without significant postoperative sedation in patients undergoing elective surgery under general anesthesia.

\section{Methods}

This study was approved by the institutional review board of Catholic University St. Vincent Hospital, Suwon, South Korea on 24 July 2012 (VC 12MISI0124)

After obtaining written informed consents from all study patients, we enrolled 132 female patients (ASA physical status I-II, aged 18 to 60 years) who were scheduled to undergo elective laparoscopic total hysterectomy under general anesthesia. Obese patients (BMI > 27) and those with hypo- or hyperthyroidism, cardiopulmonary disease, psychological disorders, blood transfusion during surgery, an initial body temperature above $38.0^{\circ} \mathrm{C}$ or below $36.0^{\circ} \mathrm{C}$ were excluded from the study.

Patients did not receive premedication. On arrival at the preanesthetic care unit, patients were assigned randomly to one of four groups by a computer-generated randomization table: group $S$ (saline), group D0.5 (dexmedetomidine $0.5 \mu \mathrm{g} / \mathrm{kg}$ ), group D0.75 (dexmedetomidine $0.75 \mu \mathrm{g} / \mathrm{kg}$ ), and group D1.0 (dexmedetomidine $1.0 \mu \mathrm{g} / \mathrm{kg}$ ). Nurses who did not participate in this study prepared the study drugs, all of which were diluted in total volume $50 \mathrm{ml}$ of normal saline.

In the operating room, routine monitors were applied, including a blood pressure cuff, electrocardiogram, pulse oximeter, and capnogram. Tympanic temperature was measured to determine baseline values. Anesthesia was induced with propofol 2-2.5 $\mathrm{mg} / \mathrm{kg}$ and rocuronium $0.6 \mathrm{mg} / \mathrm{kg}$. After endotracheal intubation, anesthesia was maintained with $6-8 \%$ desflurane and $50 \%$ nitrous oxide in oxygen. Mechanical ventilation was adjusted to maintain end-tidal carbon dioxide tension at $30-35 \mathrm{mmHg}$.

Operation room temperature was kept between 21-22 ${ }^{\circ} \mathrm{C}$. Patients were only covered with surgical drapes and none of the patients were actively warmed during or after anesthesia. Supplemental doses of rocuronium were administered at the discretion of the anesthesiologist. Approximately 30 minutes before the anticipated completion of surgery, an anesthesiologist who was blind to the drug and group allocation administered the study drug over 10 minutes. Any intraoperative narcotics were not administered in all patients. Local anesthetic was not infiltrated into laparoscopic incision sites. Ephedrine $(10 \mathrm{mg}$ i.v. bolus) was given for hypotension (systolic pressure $<80$ $\mathrm{mmHg}$ ) and atropine (0.5 mg i.v._bolus) was given for bradycardia ( $\mathrm{HR}<50 \mathrm{~min}$ ).

Five minutes before the anticipated end of surgery, the desflurane concentration was decreased to 5 vol\%. Desflurane was discontinued at the end of surgery and the lungs were ventilated with $100 \%$ oxygen. Residual neuromuscular blockade was reversed with glycopyrrolate $6 \mu \mathrm{g} / \mathrm{kg}$ and pyridostigmine 0.15 $\mathrm{mg} / \mathrm{kg}$. The trachea was extubated when the patient's respiratory effort was adequate. Extubation time (from termination of desflurane until extubation), duration of anesthesia and duration of surgery were noted. In the PACU, all patients were monitored, received oxygen via a face mask and were covered with a cotton blanket. An anesthesiologist who was blind to the study drug observed the patient for shivering, sedation, first analgesic rescue time and pain score (100 mm visual analogue scale (VAS)). Shivering was assessed every $10 \mathrm{~min}$ over $40 \mathrm{~min}$ in the PACU and graded as $0=$ no shivering, $1=$ mild fasciculation of the face or neck, $2=$ visible tremor involving more than one muscle group, 3 = gross muscular activity involving the entire body. The patients were administered meperidine $25 \mathrm{mg}$ when their shivering score was 2 or higher and patients who had a pain score more than $40 \mathrm{~mm}$ were administered $1 \mu \mathrm{g} / \mathrm{kg}$ intravenous fentanyl.

Postanesthetic sedation was checked every 20 min over $40 \mathrm{~min}$ in the PACU and graded, using the Modified Observer's Assessment of Alertness/Sedation (MOAA/S) Score, as $0=$ does not respond to pain, $1=$ does not respond to mild prodding or shaking, 2 = responds only after mild prodding or 
shaking, 3 = responds only after name is called loudly and/or repeatedly, $4=$ lethargic response to name spoken in normal tone, 5 = responds readily to name spoken. Recovery room temperature was kept between $22-23^{\circ} \mathrm{C}$.

\section{Statistical Analysis}

The number of patients required in each group was determined after a power calculation based on data from a previous investigation of dexmedetomidine and its influence on the incidence of postoperative shivering. We anticipated a difference of $35 \%$ in the incidence of shivering between the control and treated groups as being clinically meaningful. Hence, we calculated that 28 patients were required in each group for a type I error of 0.05 and a type II error of 0.2 . We increased the recruitment by $20 \%$ to compensate unexpected loss. Of the 132 recruited patients for this study, 12 patients were excluded due to transfusion or change to open abdominal hysterectomy. Of the remaining patients, 30 patients in each group received allocated interventions. All results are expressed as means (SD). Statistical analysis was performed using the SPSS (version 15.0; SPSS Inc., Chicago, IL, USA). The incidence of shivering and number of patients requiring rescue anlagesia were compared among different groups using the $\chi^{2}$ test. One-way ANOVA followed by Tukey's test was used to analyze the differences among the groups in demographic profiles, temperature changes, and extubation time. The within-group data were analyzed using repeated-measures analysis of variance followed by Bonferroni's test. $\mathrm{P}$ value $<0.05$ was considered statistically significant.

\section{Results}

Patient characteristics, duration of surgery, duration of anesthesia and temperatures of operating and recovery rooms were similar among the four groups $(\mathrm{P}>0.05$, Table 1$)$.
The number of patients receiving ephedrine during the operation was not different among the four groups. However, significantly more patients in the groups D0.75 and $1.0 \mu \mathrm{g} / \mathrm{kg}$ needed atropine to treat intraoperative bradycardia compared to the placebo group (Table 1).

Extubation time was longer in groups D0.75 and D1.0 as compared to group $S(P<0.05$, Table 1$)$. Tympanic temperature after induction of anesthesia was comparable in all the groups; However, tympanic temperature at 40 minutes postoperatively in the recovery room was found to be significantly higher in group $\mathrm{S}$ than in the other dexmedetomidine groups ( $\mathrm{P}$ $<0.05$, Table 2)

Table 3 shows the grades of shivering in the four groups. The number of patients experiencing shivering was the highest in group $S$ where 19 out of 30 $(63 \%)$ patients shivered. On the other hand, $12(40 \%)$, $4(13 \%)$ and $5(17 \%)$ patients shivered in groups D0.5, D0.75 and D1.0 respectively.

More patients in group S experienced significant shivering requiring treatment compared to groups D0.75 and D1.0 ( $\mathrm{P}<0.05, \mathrm{P}<0.001$, Table 4). No patients in group D1.0 and two patients in group D0.75 required meperidine, while ten patients in group $S$ needed treatment for their shivering episodes.

Table 5 shows the number of patients requiring rescue analgesia at some point during the study period. More patients in group $S$ required rescue analgesia compared to group D0.75 and D1.0 $(\mathrm{P}<0.001$, Table 5). Time to rescue analgesia in group D1.0 was significantly longer than that in group $S(P<0.001)$ and the time to rescue analgesia was the shortest in group $\mathrm{S}$ and the longest in group D1.0 (Table 5).

The MOAA/S was significantly lower in the dexmedetomidine groups compared with the saline group on arrival in the recovery room $(\mathrm{P}<0.05$, Table 6) but there were no significant differences among the groups at $20 \mathrm{~min}$ and $40 \mathrm{~min}$ after arrival in the PACU.

Table I. Patient characteristics and perioperative data.

\begin{tabular}{lllll}
\hline & Group S $(\mathrm{n}=30)$ & Group D0.5 $(\mathrm{n}=30)$ & Group D0.75 $(\mathrm{n}=30)$ & Group D1.0 $(\mathrm{n}=30)$ \\
\hline Age $(\mathrm{yr})$ & $45.6(5.3)$ & $46.5(7.3)$ & $45.7(4.2)$ & $45.4(5.1)$ \\
Weight $(\mathrm{kg})$ & $58.3(7.3)$ & $56.4(7.2)$ & $58.2(7.0)$ & $55.5(6.2)$ \\
Height $(\mathrm{cm})$ & $160(4)$ & $157(4)$ & $159(4)$ & $158(5)$ \\
ASA grade (I/II) & $23 / 7$ & $26 / 4$ & $28 / 2$ & $27 / 3$ \\
Duration of surgery (min) & $109(22)$ & $111(27)$ & $106(28)$ & $105(24)$ \\
Duration of anesthesia $(\mathrm{min})$ & $86(20)$ & $89(26)$ & $85(26)$ & $86(22)$ \\
OR temperature $\left({ }^{\circ} \mathrm{C}\right)$ & $21.2(0.5)$ & $21.2(0.5)$ & $21.1(0.6)$ & $21.2(0.5)$ \\
Recovery room temp $\left({ }^{\circ} \mathrm{C}\right)$ & $22.3(0.3)$ & $22.2(0.4)$ & $4.4(0.3)$ & $22.2(0.4)$ \\
Extubation time $(\mathrm{min})$ & $3.1(0.9)$ & $3.8(1.2)$ & $6^{*}$ & $4.6^{*}(1.3)$ \\
Patients receiving atropine & 0 & 3 & 2 & $5^{*}$ \\
Patients receiving ephedrine & 0 & 1 & 2 & 2 \\
\hline
\end{tabular}

Values are mean (SD). ${ }^{*} \mathrm{P}<0.05$ compared with group $\mathrm{S}$. $\mathrm{P}<0.05$ compared with group D0.5. 
Table 2. Tympanic temperature $\left({ }^{\circ} \mathrm{C}\right)$.

\begin{tabular}{lllll}
\hline & \multicolumn{1}{c}{ Group S $(\mathrm{n}=30)$} & \multicolumn{1}{c}{ Group D0.5 $(\mathrm{n}=30)$} & Group D0.75 $(\mathrm{n}=30)$ & Group D1.0 $(\mathrm{n}=30)$ \\
\hline After induction (baseline) & $37.0(0.2)$ & $37.0(0.2)$ & $37.0(0.2)$ & $37.0(0.2)$ \\
Before drug administration & $36.2(0.3))^{*}$ & $36.1(0.3)^{*}$ & $36.1(0.4)^{*}$ & $36.3(0.3)^{*}$ \\
After extubation & $36.0(0.3)^{*}$ & $35.7(0.4)^{*}+$ & $35.8(0.4)^{*}$ & $35.9(0.3)^{*}$ \\
Postoperative 0 min & $36.0(0.4)^{*}$ & $35.7(0.4)^{* \dagger}$ & $35.8(0.4)^{*}$ & $35.9(0.3)^{*}$ \\
Postoperative 20 min & $36.1(0.4)^{*}$ & $35.7(0.4)^{* \dagger}$ & $35.7(0.4)^{* \dagger}$ & $35.9(0.4)^{*}$ \\
Postoperative 40 min & $36.1(0.4)^{*}$ & $35.8(0.4)^{* \dagger}$ & $35.7(0.3)^{* \dagger}$ & $35.8(0.4)^{* \dagger}$ \\
\hline
\end{tabular}

Values are mean (SD). ${ }^{*} \mathrm{P}<0.05$ compared with baseline. ${ }^{\dagger} \mathrm{P}<0.05$ compared group $\mathrm{S}$.

Table 3. The grades of shivering in various groups.

\begin{tabular}{lllll}
\hline Grades & $\begin{array}{l}\text { Group S } \\
(\mathrm{n}=30)\end{array}$ & $\begin{array}{l}\text { Group D0.5 } \\
(\mathrm{n}=30)\end{array}$ & $\begin{array}{l}\text { Group D0.75 } \\
(\mathrm{n}=30)\end{array}$ & $\begin{array}{l}\text { Group D1.0 } \\
(\mathrm{n}=30)\end{array}$ \\
\hline 0 & $11(37)$ & $18(60)$ & $26^{* \dagger}(86)$ & $25^{* \dagger}(83)$ \\
1 & $9(30)$ & $6(20)$ & $2^{\ddagger}(7)$ & $5(17)$ \\
2 & $10(33)$ & $6(20)$ & $2^{\ddagger}(7)$ & $00^{\ddagger \ddagger}(0)$ \\
3 & $0(0)$ & $0(0)$ & $0(0)$ & $0(0)$ \\
\multicolumn{7}{l}{ Values are number of patients (proportion). ${ }^{*} \mathrm{P}<0.001$ compared with group } \\
S. $+\mathrm{P}<0.05$ compared with group D0.5. $\neq \mathrm{P}<0.05$ compared with group S.
\end{tabular}

Table 4. Grades of shivering according to requirement of treatment.

\begin{tabular}{lllll}
\hline Grades & \multicolumn{3}{c}{ Group S Group D0.5 GroupD0.75 Group } \\
& $(\mathrm{n}=30)$ & $(\mathrm{n}=30)$ & $(\mathrm{n}=30)$ & $\begin{array}{l}\mathrm{D} 1.0 \\
(\mathrm{n}=30)\end{array}$ \\
\hline $\begin{array}{l}\text { 0 or } 1 \text { ( not requir- } \\
\text { ing treatment) }\end{array}$ & 20 & 24 & $28^{*}$ & $30^{\dagger}$ \\
$\begin{array}{l}2 \text { or } 3 \text { ( requiring } \\
\text { treatment })\end{array}$ & 10 & 6 & $2^{*}$ & $0^{\dagger}$ \\
${ }^{*} \mathrm{P}<0.05$ compared with group S. ${ }^{+} \mathrm{P}<0.001$ compared with group S.
\end{tabular}

Table 5. Analgesic requirements.

\begin{tabular}{lllll}
\hline & $\begin{array}{l}\text { Group S } \\
(\mathrm{n}=30)\end{array}$ & $\begin{array}{l}\text { Group } \\
\mathrm{D} 0.5 \\
(\mathrm{n}=30)\end{array}$ & $\begin{array}{l}\text { Group } \\
\mathrm{D} 0.75 \\
(\mathrm{n}=30)\end{array}$ & $\begin{array}{l}\text { Group } \\
\mathrm{D} 1.0 \\
(\mathrm{n}=30)\end{array}$ \\
\hline $\begin{array}{l}\text { Time to rescue anal- } \\
\text { gesia; min }\end{array}$ & $17.0(7.4)$ & $22.0(7.5)$ & $22.0(7.7)$ & $28.5(7.7)^{*}$ \\
$\begin{array}{l}\text { Patients requiring } \\
\text { rescue analgesia ; no. } \\
(\%)\end{array}$ & $28(93)$ & $23(76)$ & $15(50)^{*}$ & $13(43)^{*} \dagger$ \\
\hline $\begin{array}{l}\text { Values are mean (SD) or number of patients (proportion).* } \mathrm{P}<0.001 \mathrm{com}- \\
\text { pared with group S. }+\mathrm{P}<0.05 \text { compared with group D0.5. }\end{array}$
\end{tabular}

Table 6. Postoperative MOAA/S.

\begin{tabular}{lllll}
\hline \multicolumn{5}{c}{ MOAA/S } \\
\hline & $\begin{array}{l}\text { Group S } \\
(\mathrm{n}=30)\end{array}$ & $\begin{array}{l}\text { Group D0.5 } \\
(\mathrm{n}=30)\end{array}$ & $\begin{array}{l}\text { Group D0.5 } \\
(\mathrm{n}=30)\end{array}$ & $\begin{array}{l}\text { Group } \\
\text { D1.0 } \\
(\mathrm{n}=30)\end{array}$ \\
& & $3.6^{*}(1.0)$ & $3.2^{\dagger}(1.2)$ & $\begin{array}{l}3.2^{\dagger}(1.2) \\
4.9(0.4)\end{array}$ \\
$\begin{array}{l}\text { Arrival at PACU } \\
20 \text { min after arrival } \\
\text { at PACU }\end{array}$ & $5(0)$ & $5(0)$ & $4.9(0.2)$ & \\
$\begin{array}{l}40 \text { min after arrival } \\
\text { at PACU }\end{array}$ & $5(0)$ & $5(0)$ & $5(0)$ & $5(0)$ \\
\hline
\end{tabular}

Values are mean (SD). ${ }^{*} \mathrm{P}<0.05$ compared with group S. $\dagger \mathrm{P}<0.001 \mathrm{com}-$ pared with group $\mathrm{S}$.

\section{Discussion}

In this study, we found that dexmedetomidine 0.75 or $1.0 \mu \mathrm{g} / \mathrm{kg}$ significantly reduced the incidence and severity of postoperative shivering compared with saline or dexmedetomidine $0.5 \mu \mathrm{g} / \mathrm{kg}$.

Shivering is a frequent and undesirable complication of anesthesia during the postoperative period. Due to undesirable effects such as hypoxia, lactic acidosis, and increased intraocular pressure, postanesthetic shivering needs to be prevented. $1,3,11$

Dexmedetomidine is a potent $\mathrm{a}_{2}$-adrenoceptor agonist with an eight times higher affinity for the $\mathrm{a}_{2}$-adrenoceptor than clonidine. Dexmedetomidine at a dose of $1 \mu \mathrm{g} / \mathrm{kg}$ has been shown to be useful for prevention of postanesthetic shivering. Elvan et al. compared a loading dose of $1 \mu \mathrm{g} / \mathrm{kg}$ and continuous infusion of $0.4 \mu \mathrm{g} / \mathrm{kg} / \mathrm{hr}$ of dexmedeomidine with placebo for preventing postanesthetic shivering. ${ }^{8}$ In that study, the shivering incidence was $18 \%$ with dexmedetomidine and $53 \%$ with placebo. Our results are comparable to those with shivering noted in $14 \%$ and $17 \%$ of patients in the dexmedetomidine 0.75 $\mu \mathrm{g} / \mathrm{kg}$ and $1.0 \mu \mathrm{g} / \mathrm{kg}$ groups respectively and $63 \%$ in the placebo group. The incidence of shivering in the dexmedetomidine $0.5 \mu \mathrm{g} / \mathrm{kg}$ group was $40 \%$, which was lower than that in the placebo group but the difference was not significant. Bicer et al. reported that intraoperative intravenous dexmedetomidine 1.0 $\mu \mathrm{g} / \mathrm{kg}$ reduces postanesthetic shivering with effects comparable to those of meperidine $0.5 \mathrm{mg} / \mathrm{kg} .{ }^{10} \mathrm{In}$ cidences of postanesthetic shivering in the meperidine and dexmedetomidine group were $10 \%$ and $15 \%$, respectively, compared with $55 \%$ in the placebo group. Meanwhile, Blaine Easley et al. reported that dexmedetomidine $0.5 \mu \mathrm{g} / \mathrm{kg}$ was effective for treatment of postanesthetic shivering in children. ${ }^{12}$ In the present study we aimed to find the optimal dose for prophylaxis of postanesthetic shivering by comparing dexmedetomidine in doses of $0.5,0.75$ and $1.0 \mu \mathrm{g} / \mathrm{kg}$ in adults undergoing surgical procedure under general anesthesia. 
Intraoperative hypothermia is the major risk factor for post-anesthetic shivering, but shivering can occur in patients who are normothermic at the end of the surgery. ${ }^{13,14}$ In our study, tympanic temperatures in the operation room started to decrease after induction and were lower than the baseline temperatures in all groups. In the recovery room, patients in the dexmedetomidine groups were hypothermic and their body temperatures were mostly lower than those of patients in the saline group, who were normothermic. However, the incidence and severity of shivering patients were significantly greater in saline group. Dexmedetomidine has been reported to reduce the core temperature and our results are consistent with this findings. ${ }^{15}$ We were unable to find relationship between the tympanic temperature values and postanesthetic shivering.

Nausea and vomiting are common after general anesthesia. Nausea is also one of the adverse effects of dexmedetomidine. However, there are also studies showing no difference of dexmedetomidine compared with placebo for nausea. ${ }^{8}$ In our study, the nausea and vomiting incidence did not differ among the four groups.

Bradycarida is one of the known hemodynamic effects of dexmedetomidine. In our study, three, six and five patients in the groups of dexmedetomidine $0.5,0.75$, and $1.0 \mu \mathrm{g} / \mathrm{kg}$ received atropine respectively. The use of atropine for bradycardia should be considered here because anticholinergic premedication increases the incidence of post anesthetic shivering by increasing vasoconstriction and shivering thresholds. ${ }^{16}$ Although more patients in the dexmedtomidine group received atropine compared to placebo group, fewer patients shivered.

Dexmedetomidine has sedative and analgesia-sparing effects via central actions in the locus coeruleus and in the dorsal horn of the spinal cord, respectively. ${ }^{17}$

Bicer et al. demonstrated that patients who received dexmedetomidine demonstrated a prolonged extubation time and higher sedation scores compared with placebo patients. ${ }^{10}$ The present study showed that extubation time was prolonged significantly in the dexmedetomidine 0.75 and $1.0 \mu \mathrm{g} / \mathrm{kg}$ groups. This prolonged extubation time, which appeared to be dose dependent, was longest in the dexmedetomidine $1.0 \mu \mathrm{g} / \mathrm{kg}$ group and shortest in the dexmedetomidine $0.5 \mu \mathrm{g} / \mathrm{kg}$ group. Extubation time in the dexmedetomidine $0.5 \mu \mathrm{g} / \mathrm{kg}$ group was longer than that in the saline group but the difference was not significant.

The patients in dexmedetomidine groups in our study had lower MOAA/S postoperative sedation scores upon arrival in the recovery room compared with the saline group. But beginning 20 minutes after arrival at the PACU, the sedation scores were not different among the groups.

Considering the analgesic effect, dexmedetomidine $0.5 \mu \mathrm{g} / \mathrm{kg}$ was not as effective as dexmedetomidine 0.75 or $1.0 \mu \mathrm{g} / \mathrm{kg}$. The effect of dexmedetomidine $1.0 \mu \mathrm{g} / \mathrm{kg}$ on analgesia was more consistent than other dexmedetomidine groups. The lowest patients required rescue analgesia in the dexmedetomidine 1.0 $\mu \mathrm{g} / \mathrm{kg}$ group and the time to rescue analgesic was the longest in this group.

There are some limitations in our study. First, the sample population consisted only young adult female patients who were relatively healthy. It needs to be determined whether the present findings can be generalized to other age groups and the male sex. Second, administration of meperidine can influence to analgesic rescue during postoperative period but we made no attempt to assess it. However, the number of patients who received analgesic rescue was the most in the saline group. The time to rescue analgesia in the saline group was the shortest among the four groups. Therefore, in our study, it doesn't seem like meperidine affected analgesic rescue significantly.

We conclude that dexmedetomidine possesses good antishivering properties as well as an analgesic effect at a dose of 0.75 or $1.0 \mu \mathrm{g} / \mathrm{kg}$. Though sedation in the immediate recovery period and delayed extubation time with dexmedetomidine appeared, they did not have any major clinical impacts on the overall recovery from anesthesia.

\section{Acknowledgements}

The authors appreciate the support in the statistical analysis of SH Jung.

\section{Competing Interests}

The authors have declared that no competing interest exists.

\section{References}

1. Buggy DJ, Crossley AW. Thermoregulation, mild perioperaitve hypothermia and postanaesthetic shivering. Br J Anaesth 2000; 84: 615-28.

2. Macario A, Weinger M, Carney $S$ et al. Which clinical anesthesia outcomes are important to avoid? The perspective of patients. Anesth Analg 1999; 89: 652-8.

3. Macintyre PE, Pavlin EB, Dwersteg JF. Effect of meperidine on oxygen consumption, carbon dioxide production, and respiratory gas exchange in postanesthesia shivering. Anesth Analg 1987; 66: 751-5.

4. Frank SM, Fleisher LA, Olson KF et al. Multivariate determinants of early postoperative oxygen comsumption in elderly patients. Effect of shivering, body temperature, and gender. Anesthesiology 1995; 83: 241-9.

5. Singh P, Dimitriou V, Mahajan RP et al. Double-blind comparison between doxapram and pethidine in the treatment of postanaesthetic shivering. Br J Anaesth 1993; 71: 685-8.

6. Dal D, Kose A, Honca $\mathrm{M}$ et al. Efficacy of prophylactic ketamine in preventing postoperative shivering. Br J Anaesth 2005; 95: 189-92.

7. Mohta M, Kumari N, Tyagi A et al. Tramadol for prevention of postanaesthetic shivering: a randomised double-blind comparison with pethidine. Anaesthesia 2009; 64: 141-6. 
8. Elvan EG, Qc B, Uzun S et al. Dexmedetomidine and postoperative shivering in patients undergoing elective abdominal hysterectomy. Eur J Anaesthesiol 2008; 25: 357-64.

9. Doufas AG, Lin CM, Suleman MI et al. Dexmedetomidine and meperidine additively reduce the shivering threshold in humans. Stroke 2003; 34: 1218-23.

10. Bicer C, Esmaoglu A, Akin A et al. Dexmedeomidine and meperidine prevent postanaesthetic shivering. Eur J Anaesthesiol 2006; 23: 149-53.

11. Mahajan RP, Grover VK, Sharma SL et al. Intraocular pressure changes during muscular hyperactivity after general anesthesia. Anesthesiology 1987; 66: 419-21.

12. Blaine Easley R, Brady KM, Tobias JD. Dexmedetomidine for the treatment of postanesthesia shivering in children. Pediatr Anesth 2007; 17: 341-6.

13. Horn E-P, Sessler DI, Standl T et al. Nonthermoregulatory shivering in patients recovering from isoflurane or desflurane anesthesia. Anesthesiology 1998; 89: 878-86.

14. Panzer O, Ghazanfari N, Sessler DI et al. Shivering and shivering-like tremor during labor with and without epidural analgesia. Anesthesiology 1999; 90: 1609-16.

15. El-Tahir KE-DH. Dexmedetomidine a sedative-analgesic drug for the $21^{\text {st }}$ century. Middle East J anesthesiol 2002; 16: 577-85.

16. Greif R, Laciny S, Rajek A et al. Neither nalbuphine nor atropine possesses special anti-shivering activity. Anaesth Analg 2001; 93: 620-7.

17. Anataa R, Jaakola ML, Kallio A et al. Reduction of the minimum alveolar concentration of isoflurane by dexmedetomidine. Anesthesiology 1997; 86: 1055-60. 